\section{PWE-009 CONSTRUCT VALIDITY OF A TOOL FOR ASSESSING COMPETENCY IN POLYPECTOMY}

doi:10.1136/gut.2011.239301.272

S Gupta, ${ }^{*}$ R Man, N Suzuki, M E Vance, S Thomas-Gibson Endoscopy, Wolfson Unit for Endoscopy, St. Mark's Hospital, Harrow, UK

Introduction There is a void in the formal assessment of technical skills in polypectomy which is now considered an integral part of colonoscopy. It has been shown to reduce the incidence of colorectal cancer but does have associated complications. Polypectomy competency assessment should arguably be a part of the certification process for all endoscopists. A polypectomy competency assessment tool (Direct Observation of Polypectomy Skills-DOPyS) has been developed and its construct validity, examined.

Methods To determine construct validity of the DOPyS. Thirty-two polypectomy videos (incorporating the endoscopic view only) were collected from real patient procedures performed by two experienced ( $>1000$ colonoscopies) endoscopists (17 videos) and six intermediate level (100-500 colonoscopies) endoscopists (15 videos). The videos were edited to include only the entire polypectomy procedure, arranged in random order, and assessed blindly by two experienced endoscopy assessors. Both assessors underwent a polypectomy assessment training session using the DOPyS prior to scoring. The DOPyS incorporates a 33-point procedure-specific checklist and an overall competency score. The differences in overall competency scores (range 1-4; scores $\geq 3=$ competency) for the expert and intermediate groups were compared, and considered significant $(p$ value $<0.05)$ using Fisher's exact test.

\section{Results}

Conclusion The results of the analysis suggested that both blinded assessors were able to reliably differentiate between endoscopists of varying experience using the DOPyS (the expert group had higher scores than the intermediate group). Large-scale validation studies are required to further strengthen evidence for the use of this tool for routine polypectomy competency assessment.

Competing interests None.

Keywords Assessment, Competency, construct, polypectomy, validity.

Table 1 PWE-009 Comparison of Overall Competency Scores for the Expert and Intermediate group of Endoscopists.

\begin{tabular}{lllll}
\hline Assessor & Overall score & Expert group number of videos $(\%)$ & Intermediate group number of videos $(\%)$ & p Value \\
\hline 1 & Score $<3$ & $2(12 \%)$ & $7(47 \%)$ & 0.049 \\
& Score $\geq 3$ & $15(88 \%)$ & $8(53 \%)$ & $<0.001$ \\
2 & Score $<3$ & $1(6 \%)$ & $12(80 \%)$ & \\
\hline
\end{tabular}

